\title{
Optimization of Electrochemiluminescence Experimental Conditions for Metoclopramide Determination Based on Response Surface Methodology
}

\author{
Fuxiu Yang ${ }^{1}$, Wenjuan Zhang ${ }^{1}$, Baining Liu ${ }^{1,2}$, Yizhi Ji ${ }^{1,2}$, Youxi Zhao ${ }^{1,2}$, Kaowen Zhou ${ }^{1,2, *}$ \\ ${ }^{1}$ Biochemical Engineering College, Beijing Union University, Beijing 100023, China \\ ${ }^{2}$ Beijing Key Laboratory of Biomass Waste Resource Utilization, Beijing 100023, China \\ "E-mail: zhoukaowen@ buu.edu.cn
}

doi: $10.20964 / 2020.08 .79$

Received: 26 April 2020 / Accepted: 4 June 2020 / Published: 10 July 2020

Based on the strong enhancement effect of metoclopramide on the electrochemiluminescence signal of $\mathrm{Ru}(\mathrm{bpy}) 3^{2+}$ on the platinum electrode, a novel method for the sensitive detection of metoclopramide was established. Based on the single factor experiments, the interactions among the three factors were investigated by response surface methodology. Finally, the optimal experimental conditions for the determination of metoclopramide in a limited number of experiments are: detection potential $1.18 \mathrm{~V}$, phosphate buffer solution concentration $39.82 \mathrm{mmol} / \mathrm{L}$ and $\mathrm{pH}$ 7.69. These conditions can improve the sensitivity of the method by $4.5 \%$, which is very important for the determination of trace components. The detection limit $(3 \sigma)$ of the method was $4.0 \times 10^{-3} \mathrm{mg} / \mathrm{L}$, the linear range was $0.02-36.56 \mathrm{mg} / \mathrm{L}$, the correlation coefficient was 0.9991 , and the recoveries were $97.3 \%-102.4 \%$. This method is simple, rapid, sensitive and with less injection.

Keywords: Electrochemiluminescence; Metoclopramide; Response surface methodology; Optimization

\section{$\underline{\text { FULL TEXT }}$}

(C) 2020 The Authors. Published by ESG (www.electrochemsci.org). This article is an open access article distributed under the terms and conditions of the Creative Commons Attribution license (http://creativecommons.org/licenses/by/4.0/). 